\title{
Manajemen Budaya Organisasi dan Kepuasan Kerja Sebagai Prediktor Kinerja Guru
}

\section{Organizational Culture Management and Job-Satisfaction As Teacher Job-Performance Predictors}

\author{
Wesly Hutabarat \\ Jurusan Kimia, Fakultas MIPA, Universitas Negeri Medan, Medan-Indonesia \\ *Korespondensi: barathuta@gmail.com
}

\begin{abstract}
Abstrak: Penelitian ini adalah penelitian kausal yang ditujukan untuk mengetahui dan mengungkap efek langsung dan tidak langsung budaya organisasi dan kepuasan kerja terhadap kinerja. Sebanyak 143 dari 645 guru sekolah menengah umum yang dipilih dari 10 sekolah menengah umum dengan stratified random sampling techmiques. Sampel guru kelas yang dipilih adalah guru yang memiliki pengalaman mengajar setidaknya 10 tahun, dan telah disertifikasi sebagai guru profesional dan menerima tunjangan sertifikasi secara terus menerus, kecuali guru bimbingan dan konseling. Ditemukan bahwa pengaruh langsung Budaya Organisasi terhadap Kepuasan kerja ada sebesar 32.50\%, sedangkan efek langsung Kepuasan Kerja dan Budaya Organisasi terhadap Kinerja ada sebesar16,70\% dan 35.60\%. Pengaruh tak langsung Budaya Organisasi terhadap Kinerja melalui Kepuasan Kerja ada sebesar 14,50\%. Jadi pengaruh total Budaya Organisasi terhadap Kinerja adalah 33,3\%. Berdasarkan temuan penelitian di atas dapat disimpulkan bahwa budaya organisasi, struktur organisasi dan kepuasan kerja memberi dampak positif terhadap kinerja guru SMA Kota Medan.
\end{abstract}

Kata kunci: Budaya organisasi, kepuasan kerja, kinerja

\begin{abstract}
This study is a causal research which is intended to find out direct and indirect effects of organizational culture and job-satisfaction on job-performance. As many as 143 of 645 public high school teachers were selected from 10 pulic high schools in Medan, Indonesia by stratified random sampling techniques. The classroom teacher samples selected were teachers who have teaching experiences for at least 10 years, and have been certified as professional teachers and received certification fees continuously, except for guidance and counseling teachers. It was found that the direct effect of Organizational Culture on Job Satisfaction is 32.50\%, while the direct effect of Job Satisfaction and Organizational Culture on Performance is $16.70 \%$ and $35.60 \%$ respecively. The indirect effect of Organizational Culture on Performance through Job Satisfaction is 14.50\%. So the total effect of Organization Culture on Performance is 33.3\%. Based on the findings, it can be concluded that organizational culture, organizational structure and job satisfaction have a positive impact on the teacher job-performance of high school teachers in Medan.
\end{abstract}

Keywords: Job-Performance, Job-Satisfaction, Organizational Culture

\section{PENDAHULUAN}

Kinerja didefinisikan sebagai hasil kerja dalam mencapai tujuan organisasi di mana seseorang bekerja. Prestasi kerja guru menentukan kualitas pekerjaan mereka dalam meningkatkan dan mengembangkan pertumbuhan Pendidikan Nasional yang dapat diidentifikasi berdasarkan pencapaian tujuan pengajaran.

Temuan penelitian baru-baru ini menunjukkan bahwa kinerja guru SMA di Medan tergolong rendah dan berdasarkan Peringkat Kinerja Uji Prestasi Internasional, Indonesia berada di peringkat ke-50 dari 87 negara (Tienken, 2008). Selain itu, program pada penilaian siswa internasional (Pisa, 2012) menunjukkan bahwa Indonesia berada di peringkat 64 dari 65 negara. Untuk mengatasi hal itu, Pemerintah Indonesia telah mencoba untuk meningkatkan kualitas pendidikan (Upu, 2014) dan kinerja guru melalui perubahan administratif dan pengajaran.

Langkah yang diambil pemerintah Indonesia untuk meningkatkan kinerja guru adalah melalui program sertifikasi guru. Program ini merupakan program pelatihan guru in-service training yang umumnya dilakukan selama 9 hari kerja. Hasil program sertifikasi guru meningkatkan motivasi kerja guru yang dapat dilihat dari ketertarikan mereka untuk menempuh pendidikan tingkat tinggi (gelar sarjana dan magister). Juga diprediksi bahwa para guru termotivasi untuk mengadakan konferensi ilmiah bersama di bidang studi mereka sendiri untuk memenuhi persyaratan program sertifikasi, dan dalam hal ini meningkatkan kualitas guru. 
Sayangnya, ditemukan bahwa program sertifikasi guru tidak berpengaruh terhadap kinerja guru (Fahmi et al., 2011).

Sejalan dengan program sertifikasi guru, ternyata guru yang mendapatkan sertifikasi akan mendapatkan tambahan biaya bulanan yang disebut tunjangan sertifikasi yang akan memberi dampak pada kepuasan kerja guru, artinya karyawan yang puas adalah karyawan produktif (Thierry, 1998). Oleh karena itu, kepuasan kerja dapat dilihat sebagai prekursor kinerja (Miles dan Sledge, 2006).

Diketahui bahwa, indikator evaluasi kinerja guru terdiri dari (1) rencana dan bahan pengajaran, (2) prosedur kelas, dan (3) keterampilan interpersonal (Barge, 2012; Wilson dan Barney, 2011; Rix, 2010; Depdiknas, 2008). Umumnya, pendidik hanya mempertimbangkan ketiga indikator diatas dalam menentukan kinerja guru, namun belakangan ini, banyak pendidik mencoba menggunakan teori perilaku organisasi ke dalam sistem pendidikan karena keberhasilan organisasi dalam mengukur kinerja manajerial. Misalnya, perusahaan Cromble Pty, Coco-Mat, mengubah budaya organisasi dan struktur organisasi mereka untuk meningkatkan produktivitas organisasi (Robin dan Coultier, 2007). Keberhasilan organisasi dalam menggunakan teori perilaku organisasi kedalam produktivitas manajerial, sehingga pendidik mencoba mempertimbangkan apakah probabilitas mekanisme organisasi, mekanisme kelompok, karakteristik individu dan mekanisme individual dapat mempengaruhi kinerja guru.

Jugde dkk. (2001) menemukan bahwa ada hubungan positif antara kepuasan kerja dan kinerja, dan ternyata hubungan tersebut lebih tinggi pada pekerja profesional. Khain (2005) menemukan bahwa keberhasilan organisasi sebagian ditentukan oleh kemampuan individu untuk mengadopsi budaya organisasi di tempat kerja, karena budaya organisasi mengandung prinsip dasar yang menentukan bagaimana karyawan berperilaku didalam organisasi.

Selanjutnya, Sempane et al. (2002) menemukan bahwa budaya organisasi mempengaruhi kepuasan kerja. Sehubungan dengan temuan ini, Ojo (2009) menemukan bahwa budaya organisasi secara langsung mempengaruhi kinerja, oleh karena itu, keberhasilan organisasi bergantung pada budaya organisasi (Serrat, 2009). Ehrenberg (2003) menemukan bahwa pekerja yang W.Hutabarat berpendidikan lebih tinggi akan memiliki kepuasan kerja yang lebih tinggi dibandingkan dengan pekerja yang kurang berpendidikan. Akibatnya, diperkirakan bahwa kinerja guru SMA cukup tinggi Diketahui juga bahwa budaya organisasi memiliki peran penting dalam meningkatkan kepuasan kerja guru (Sabri et al., 2011).

Berdasarkan pembahasan di atas, diasumsikan bahwa kinerja guru dapat ditentukan oleh budaya organisasi dan kepuasan kerja. Dengan demikian penelitian ini ditujukan untuk 1. mengetahui pengaruh langsung budaya organisasi terhadap kinerja, 2. pengaruh langsung kepuasan kerja terhadap kinerja dan 3. untuk mengetahui pengaruh tidak langsung budaya organisasi terhadap kinerja melalui kepuasan kerja.

\section{Kajian teoritis kinerja}

Kinerja didefinisikan sebagai pencapaian hasil kerja karyawan yang sesuai dengan tujuan organisasi. Kinerja kerja guru biasanya dipengaruhi oleh fasilitas sekolah, ukuran kelas, gaya kepemimpinan, strategi motivasi dan semangat guru (Adejumobi dan Ojikutu, 2013). Umumnya, perilaku kerja yang terukur diklasifikasikan sebagai kinerja. Hal ini biasanya dilakukan untuk (1) mengetahui informasi yang kredibel, relevan, dan berguna, sehingga dapat digunakan dalam proses pengambilan keputusan mengenai kinerja organisasi saat ini dan masa depan, (2) mengidentifikasi kinerja dan pertumbuhan organisasi, (3) rencana dan melaksanakan pelatihan dan pengembangan, (4) melakukan remunerasi dan penghargaan, dan (5) merancang pengembangan karir dan suksesi (Chiepe, 2004).

Temuan penelitian menunjukkan bahwa kepuasan kerja mempengaruhi kinerja kerja (Iffinedo, 2004; Ladebo, 2005; Slocum et al., 2009; Ololube, 2009). Selain itu, diyakini bahwa penghargaan dapat dilihat sebagai moderator antara kepuasan kerja dan kinerja. Oleh karena itu, pemberian reward berupa gaji sertifikasi dapat dilihat sebagai moderator kepuasan kerja terhadap kinerja.

Luthans dan Stajkovic (2001) menemukan bahwa pengakuan secara positif mempengaruhi kinerja. Akibatnya, pengakuan profesional guru pada awalnya bisa mempengaruhi kinerja guru. Dengan membayar sertifikasi guru secara rutin, dapat dipandang sebagai pengakuan pemerintah terhadap profesionalisme guru yang dapat 
meningkatkan harga diri guru di mata masyarakat.

Evaluasi kinerja guru diduga dapat dilakukan dengan mempertimbangkan rubrik berikut ini: (1) pengetahuan profesional, (2) perencanaan pengajaran, (3) strategi mengajar, (4) pengajaran dan remedial individu, (5) teknik evaluasi, (6) umpan balik, (7) lingkungan belajar mengajar, (8) tantangan dalam lingkungan akademis, (9) profesionalisme, dan (10) komunikasi (Barge,. 2012).

\section{Budaya organisasi}

Budaya organisasi didefinisikan sebagai hubungan sosial antara anggota organisasi yang dianggap sebagai cara hidup dalam sebuah organisasi (Depdiknas, 2008; Schein, 2004). Secara umum, budaya organisasi berbeda dari satu organisasi ke organisasi lainnya, karena biasanya dikembangkan dalam suatu organisasi untuk jangka waktu yang panjang. Budaya organisasi memungkinkan anggota organisasi untuk mengkoordinasikan kegiatan secara komprehensif, memahami dan memprediksi perilaku karyawan, kepercayaan, dan motivasi kerja karyawan.

Schein (2004) menekankan bahwa budaya organisasi dapat ditentukan melalui (1) artefak, (2) norma dan nilai, (3) asumsi dasar (Colquitt et al., 2009)

Artefak bisa diamati secara langsung, misalnya seragam, cerita, jargon, dan grafik. Namun, norma dan nilai sulit untuk diamati. Norma umumnya terkait dengan nilai dan peraturan tidak tertulis yang mengharapkan anggota organisasi melakukannya didalam organisasi. Misalnya, diasumsikan bahwa siswa "buruk", akibatnya menghasilkan satu norma yang melarang mereka keluar dari sekolah tanpa izin.

Secara umum, ada lima artefak yaitu simbol, struktur fisik, bahasa, cerita, ritual, dan upacara. Simbol berkenaan dengan logo organisasi, lingkungan kerja, sedangkan struktur fisik berkaitan dengan hubungan organisasi dengan publik, hubungan manajer dengan anggota organisasi lainnya, dan demokrasi karyawan (Colquitt et al., 2009). Bahasa adalah alat komunikasi di dalam organisasi. Sementara cerita menyangkut anekdot, legenda, dan mitos yang diajarkan dari satu generasi ke generasi lainnya di dalam organisasi. Ritualis didefinisikan sebagai kegiatan sehari-hari atau mingguan W.Hutabarat dalam organisasi. Nilai-nilai yang diyakini (espoused values) berkaitan dengan norma dan filosofi organisasi yang dinyatakan secara eksplisit. Nilai ini meliputi dokumen yang diterbitkan seperti pernyataan visi dan misi organisasi, termasuk pernyataan lisan manajer yang diarahkan kepada karyawan untuk dilakukan. Asumsi dasar berkaitan dengan filosofi dan kepercayaan organisasi yang umumnya diterima tanpa pertanyaan (Colquitt et al., 2009)

Oleh karena itu, budaya organisasional diperkirakan dapat ditentukan melalui pengamatan perilaku, nilai dan kepercayaan dan asumsi dasar yang dapat diamati.

\section{Kepuasan kerja}

Kepuasan kerja didefinisikan sebagai keadaan emosional karyawan yang memuaskan sebagai hasil evaluasi manajer terhadap tugasnya yang memenuhi tujuan organisasi (Tella et al., 2007). Oleh karena itu, karyawan yang puas akan memiliki pemikiran positif atas pekerjaannya (Colquitt et al., 2009; Saari dan Judge, 2004; Tella et al., 2007).

Maslow menjelaskan bahwa ada beberapa faktor yang dapat mempengaruhi kepuasan kerja yaitu kebutuhan biologis dan fisiologis, kebutuhan keselamatan, rasa memiliki dan kebutuhan akan cinta, kebutuhan harga diri dan kebutuhan aktualisasi diri. Orang-orang akan memenuhi kebutuhan yang lebih rendah pada awalnya sebelum memenuhi kebutuhan yang lebih tinggi. (Colquitt et al., 2009). Model Maslow dapat digunakan dalam mengembangkan kepuasan kerja guru dengan mempertimbangkan kebutuhan guru di tempat kerja.

Selain itu, juga diketahui bahwa kepuasan kerja dipengaruhi oleh kepuasan gaji, kepuasan promosi, kepuasan sosial, kepuasan pengawasan, kepuasan rekan kerja, kepuasan kerja, kepuasan status dan kepuasan lingkungan (Slocum dan Hellriegel, 2009). Ditemukan bahwa temperamen secara kontinu berhubungan dengan kepuasan kerja sejak kecil sampai dewasa (Staw et al., 1986). Selain itu, kepuasan kerja anak kembar secara statistik sama (Array et al., 1989).

Ada pertanyaan yang perlu diselesaikan, yaitu mengapa kita perlu menentukan kepuasan kerja guru? Jawabannya adalah karena ternyata guru yang tidak puas kurang termotivasi untuk melakukan pekerjaannya dengan baik di kelas (Cha, 2008). Pertanyaan 
lain adalah, mengapa kita memiliki kecenderungan untuk menghasilkan guru yang kurang berkualitas dari perguruan tinggi ? Hal ini diduga disebabkan oleh siswa yang masuk ke perguruan tinggi kependidikan berasal dari siswa rangking rendah dan siswa terbaik dan tercerdas tidak memilih pendidikan sebagai pilihan karir, oleh karena itu, program kuliah guru hanya akan menghasilkan guru dengan kualitas rendah (Ballou dan Podgursky, 1998; Tetenbaum dan Mulkeen, 1986). Inilah salah satu dari banyak faktor yang menunjukkan bahwa kualitas guru merupakan faktor terpenting dalam menentukan perbedaan hasil belajar siswa (Goldhaber, 2002). Oleh karena itu, kepuasan kerja dapat dilihat sebagai faktor utama yang mempengaruhi kinerja yang menentukan keberhasilan pendidikan dan kinerja guru (Ololube, 2009).

Dengan demikian, diperkirakan kepuasan kerja guru dapat ditentukan oleh kepuasan kerja, kepuasan promosi, kepuasan sosial, kepuasan pengawasan, kepuasan rekan kerja, kepuasan kerja, kepuasan status dan kepuasan lingkungan.

\section{METODE}

Penyelidikan ini adalah merupakan penelitian kausal yang mencoba menemukan hubungan kausal antara budaya organisasi dan kepuasan kerja terhadap kinerja guru SMA di Medan. Metode penelitian yang digunakan dalam penelitian ini adalah metode survei berdasarkan pendekatan explanatory dan confirmatory.

\section{Populasi and sampel}

Populasi dalam penelitian ini adalah guru dari 10 SMA Negeri di Medan Indonesia. Sampel dipilih dengan teknik stratified random sampling. Sampel dipilih berdasarkan pengalaman mengajar guru minimal 10 tahun, kecuali guru bimbingan dan konseling. Disamping itu guru sampel telah disertifikasi dan menerima tunjangan sertifikasi secara reguler.

\section{Prosedur penelitian}

Instrumen penelitian (kuesioner budaya organisasi dan kepuasan kerja) diujicobakan kepada 30 guru di luar sampel guru, untuk mengetahui validitas dan reliabilitasnya. Instrumen budaya organisasi dan kuesioner kepuasan kerja yang divalidasi masing-masing terdiri dari 34 dan 34 item setelah divalidasi dan diuji reliabilitasnya. Sedangkan alat penilaian kinerja guru dilakukan pada 30 guru untuk mengetahui persepsi penggunaan homogenitas guru dalam menggunakan instrumen tersebut.

Setelah instrumen diujicobakan kemudian divalidasi dan diuji reliabilitasnya selanjutnya kuesioner itu didistribusikan ke 150 orang sampel guru kelas. Sebelum membagikan angket, pertama sekali dijelaskan secara lisan kepada guru sampel tentang tujuan penelitian dan menanyakan apakah ada pernyataan yang tidak jelas dalam kuesioner itu. Kuesioner dibagikan ke sampel di pagi hari sebelum kelas dimulai dan saat jam istirahat. Sebanyak 143 dari 150 kuesioner yang dikumpulkan memenuhi persyaratan sebagai data yang digunakan dalam penelitian ini. Selanjutnya, penilaian kinerja guru dilakukan selama proses belajar mengajar berlangsung.

\section{Analisis data}

Berdasarkan teori perilaku organisasi, hubungan kausal antara variabel $\mathrm{X}_{1}, \mathrm{X}_{2}$ dan $\mathrm{X}_{3}$ dapat digambarkan seperti pada Gambar 1 di bawah ini.

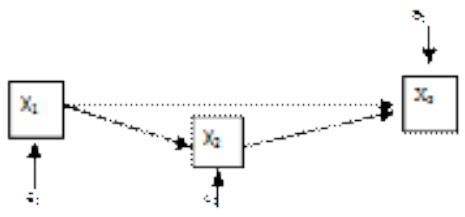

Gambar 1. Hubungan kausal variabel $\mathrm{X}_{1}, \mathrm{X}_{2}$, dan $\mathrm{X}_{3}$

$$
\begin{aligned}
\text { Dimana } \mathrm{X}_{1} & =\text { Budaya Organisasi } \\
\mathrm{X}_{2} & =\text { Kepuasan Kerja } \\
\mathrm{X}_{3} & =\text { Kinerja Guru }
\end{aligned}
$$

Data Budaya Organisasi dan kuesioner Kepuasan Kerja, dan data Kinerja diolah dan dianalisis dengan SPSS for Windows vers 21

\section{HASIL DAN PEMBAHASAN}

\section{Uji nornamitas}

Uji sampel Kolmogorov-Smirnov digunakan untuk melakukan uji normalitas, dan ditemukan Asymp. Sig. (2-tailed) budaya organisasi, kepuasan kerja dan kinerja kerja masing-masing sebesar 0,125, 0,109 dan 0,071 > 0,05, yang berarti bahwa data yang dikumpulkan berasal dari populasi terdistribusi normal seperti ditunjukkan pada 
Tabel 1.

Tabel 1. Koefisien Korelasi, Uji Regresi dan linieritas, dan Tes Kolmogorov-Smirnov

\begin{tabular}{lcccl}
\hline Koefisien Korelasi & \multicolumn{2}{c}{ Uji Linearitas } & $\begin{array}{l}\text { Tes } \\
\text { Kolmogorov- } \\
\text { Smirnov }\end{array}$ \\
\hline Variabel & $\mathrm{X}_{\mathrm{pq}}$ & Fhit. & Sig. & $\begin{array}{l}\text { Asymp. Sig } \\
\text { (2-tailed) }\end{array}$ \\
\hline $\mathrm{X}_{1}$ dan $\mathrm{X}_{2}$ & 0.399 & 1,23 & 0.21 & $\mathrm{X}_{1}=0.125$ \\
$\mathrm{X}_{1}$ dan $\mathrm{X}_{3}$ & 0.408 & 0,73 & 0.85 & $\mathrm{X}_{2}=0.109$ \\
$\mathrm{X}_{2}$ dan $\mathrm{X}_{3}$ & 0.450 & 0,98 & 0.51 & $\mathrm{X}_{3}=0.071$ \\
\hline
\end{tabular}

\section{Uji linearitas}

Uji liniaritas dilakukan dengan uji $\mathrm{F}$ distribusi pada variable penelitian $\mathrm{X}_{1}$. $\mathrm{X}_{2}$ dan $\mathrm{X}_{3}$ dan ditemukan bahwa Deviasi dari linieritas > 0,05, oleh karena itu dapat disimpulkan bahwa ketiga variabel tersebut linier seperti pada Tabel 1 di atas.

\section{Koefisien korelasi}

Penentuan koefisien korelasi $\mathrm{X}_{1}, \mathrm{X}_{2}$ dan $\mathrm{X}_{3}$ dilakukan dengan menggunakan SPSS for Windows vers 21, dan hasilnya ditunjukkan pada Tabel 1 di atas, dimana semua koefisien korelasi signifikan, dimana $t_{\text {hit. }}>t_{\text {tabel }}(5 \%)=$ 1980.

\section{Uji Dekomposisi Struktur}

Pengaruh budaya organisasi terhadap kepuasan kerja

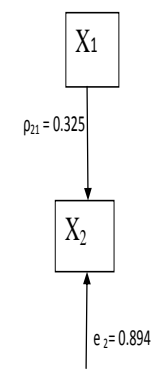

Gambar 2. Dekomposisi struktur.

Untuk menguji apakah Budaya Organisasi berpengaruh langsung terhadap Kepuasan Kerja, maka dilakukan uji Anova dan analisis jalur seperti pada Tabel 2 dan 3.

Tabel 2. Uji ANOVA variabel $\mathrm{X}_{1}$ terhadap $\mathrm{X}_{2}$

\begin{tabular}{|c|c|c|c|c|c|}
\hline Model & $\begin{array}{c}\text { Sum of } \\
\text { Squares }\end{array}$ & $\mathrm{df}$ & $\begin{array}{c}\text { Mean } \\
\text { Square }\end{array}$ & $\mathrm{F}$ & Sig. \\
\hline Regression & 2861.37 & 1 & 2861.37 & 26.7 & .000 \\
\hline $\begin{array}{l}\text { Residual } \\
\text { Total }\end{array}$ & $\begin{array}{r}15102.47 \\
17963.85\end{array}$ & $\begin{array}{r}141 \\
142\end{array}$ & 107.11 & & \\
\hline a. Dependen & ariable: $\mathrm{X}_{2}$ & & & & \\
\hline
\end{tabular}

Dari tabel Model Summary di atas diketahui besar kontribusi Budaya Organisasi terhadap Kepuasan Kerja sebesar 15,90\% atau $\mathrm{R}^{2}=0.106$, dan nilai $\mathrm{e}_{2}=$ $\sqrt{1-R^{2}=} \sqrt{1-0.325^{2}=} 0.894$.

Uji dekomposisi struktur-2

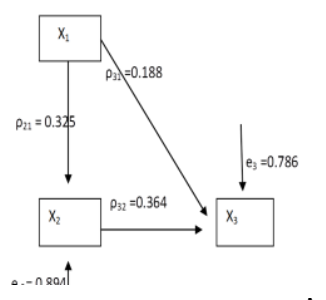

Pengaruh variabel $X_{1}$ dan $X_{2}$ terhadap $X_{3}$

Untuk mengetahui apakah kedua variabel $\mathrm{X}_{1}$ dan $\mathrm{X}_{2}$ berpengaruh secara signifikan terhadap $\mathrm{X}_{3}$ dilakukan analisis Anova dan analisis jalur, dan hasil perhitungan ditampilkan pada Tabel 3. dan 4.

Tabel 3. ANOVA $X_{1}$ dan $X_{2}$ terhadap $X_{3}$

\begin{tabular}{|cc|c|c|l|c|c|}
\hline Model & $\begin{array}{c}\text { Sum of } \\
\text { Squares }\end{array}$ & df & $\begin{array}{l}\text { Mean } \\
\text { Sq. }\end{array}$ & F & Sig. \\
\hline \multirow{2}{*}{1} & Reg & 5779.32 & 2 & 2889.6 & 19.8 & $.0^{\circ}$ \\
& Res. & 20269.3 & 140 & 144.78 & & \\
& Tot & 26048.6 & 142 & & & \\
\hline
\end{tabular}

a. Dependent Variable: $\mathrm{X}_{3}$

b. Predictors: (Constant), $\mathrm{X}_{2}, \mathrm{X}_{1}$

Dari Tabel Anova diatas diketahui bahwa taraf signifikansi $\mathrm{F}_{\text {hitung }}>\mathrm{F}_{\text {tabel }}\left(19.925>\mathrm{df}_{2 / 140}\right.$ $=3,065$ ), artinya Budaya Organisasi dan Kepuasan Kerja berpengaruh langsung positip terhadap Kinerja.

Tabel 4. Perhitungan Koefficien Jalur $\beta_{31}$ dan $\beta_{32}$

\begin{tabular}{|c|c|c|c|c|c|}
\hline \multirow[t]{2}{*}{ Model } & \multicolumn{2}{|c|}{ Unstand. Coeff. } & Stand & \multirow[t]{2}{*}{$\mathrm{t}$} & \multirow[t]{2}{*}{ Sig. } \\
\hline & B & Std. Error & Beta & & \\
\hline \multirow[b]{3}{*}{$\mathrm{X}_{2}$} & 38.48 & 10.95 & & 3.51 & .001 \\
\hline & .20 & .088 & .167 & 2.30 & .023 \\
\hline & .44 & .098 & .356 & 4.46 & .000 \\
\hline
\end{tabular}

a. Dependent Variable: $\mathrm{X}_{3}$

Pada Tabel koefficien jalur di atas diketahui bahwa koefisien jalur $\mathrm{X}_{1}$ dan $\mathrm{X}_{2}$ ke $\mathrm{X}_{3}$ masing-masing $\rho_{31}=0.167(\mathrm{t}=2,301 ; \alpha=$ o.024) dan $\rho_{32}=0,356(\mathrm{t}=4,462 ; \alpha=0,000)$. Ternyata $t$-hitung $>t$-tabel $(1,978)$, sehingga dapat disimpulkan bahwa kedua koefisien jalur signifikan. Dengan demikian besar pengaruh langsung Budaya Organisasi dan Kepuasan 
Kerja terhadap Kinerja masing-masing sebesar $16,70 \%$ dan $35.60 \%$.

Untuk mencari besar kontribusi variabel $\mathrm{X}_{1}$ dan $\mathrm{X}_{2}$ terhadap $\mathrm{X}_{3}$ ditampilkan dalam Tabel 5 .

Tabel 5. Model Summary variabel $\mathrm{X}_{2}$ dan $\mathrm{X}_{1}$

\begin{tabular}{|l|c|r|r|c|}
\hline Model & $\mathrm{R}$ & $\mathrm{R}$ Square & $\begin{array}{c}\text { Adjusted } \\
\mathrm{R} \text { Square }\end{array}$ & $\begin{array}{c}\text { Std. Er of the } \\
\text { Est. }\end{array}$ \\
\hline 1 & $.462^{\mathrm{a}}$ & .213 & .211 & 12.032 \\
\hline
\end{tabular}

a. Predictors: (Constant), $\mathrm{X}_{2}, \mathrm{X}_{1}$

Dari data di atas dapat dilihat besar total pengaruh langsung $\mathrm{X}_{1}$ dan $\mathrm{X}_{2}$ terhadap $\mathrm{X}_{3}$ ada sebesar 55,20\%. Selanjutnya nilai $\mathrm{e}_{3}=$ $\sqrt{1-R^{2}=} \sqrt{0,462=} 0,786$.

Uji keberartian $\mathrm{X}_{1}$ terhadap $\mathrm{X}_{2}$ diperoleh nilai $F_{\text {hitung }}=19.825$ dengan taraf signifikansi o.0oo, sehingga dapat disimpulkan bahwa Budaya Organisasi dan Kepuasan Kerja berpengaruh langsung positip terhadap Kinerja guru SMA.

Di dalam Tabel 5 di atas dapat dilihat bahwa besar pengaruh $\mathrm{X}_{1}$ ke $\mathrm{X}_{3}$ adalah sebesar $\rho_{31}=0.167(t=2,301 ; \alpha=0, .023)$, artinya bahwa Budaya Organisasi berpengaruh langsung positip terhadap Kinerja guru SMA sebesar $16,70 \%$.

Dekomposisi struktur kausal $\mathrm{X}_{1}, \mathrm{X}_{2}$ terhadap $\mathrm{X}_{3}$ dapat dinyatakan dalam persamaan berikut ini: $r_{13}=\rho_{31}(D E)+\rho_{32} r_{12}$ (IE).

Berdasarkan persamaan di atas maka pengaruh langsung dan tak langsung Budaya Organisasi terhadap Kinerja dapat ditentukan. Pengaruh langsung Budaya Organisasi terhadap Kinerja ada sebesar 16,70\%.. Sedangkan pengaruh tak langsung Budaya Organisasi terhadap Kinerja melalui Kepuasan Kerja adalah sebesar $\rho_{32} \mathrm{r}_{12}=0,145$ atau 14,50\%. Jadi pengaruh total Budaya Organisasi terhadap Kinerja adalah 33,3\%.

Berdasarkan hasil penelitian di atas, diketahui bahwa budaya organisasi, dan kepuasan kerja memberikan dampak positif terhadap kinerja guru SMA di Medan. Suriansyah (2014) juga menemukan bahwa budaya organisasi sekolah sangat berkorelasi dengan kinerja guru di sekolah dasar (Sempane et al., 2002). Hal ini juga didukung oleh Kane et al. (2006) yang mengumpulkan data selama enam tahun mengenai kinerja siswa dan menemukan bahwa guru bersertifikasi memiliki dampak kecil terhadap kinerja siswa. Juga dilaporkan bahwa ada dampak positif kepuasan kerja guru terhadap kualitas pendidikan (Michaelowa dan Wittmann, 2014).

Pengaruh budaya organisasi terhadap kinerja dan kepuasan kerja masing-masing sebesar $23,20 \%$ dan $18,60 \%$. Pada saat yang sama, pengaruh tidak langsung budaya organisasi terhadap kinerja adalah 11,80\%. Oleh karena itu, pengaruh total budaya organisasi dan kepuasan kerja terhadap kinerja adalah 53,60\%, Demikian pula, Suriansyah (2014) melaporkan bahwa budaya organisasi secara langsung dan tidak langsung mempengaruhi kinerja guru melalui komitmen guru masing-masing sebesar $10,10 \%$, dan $16,90 \%$.

Hasil penelitian menunjukkan bahwa budaya organisasi memberikan kontribusi yang cukup tinggi terhadap kepuasan kerja. Namun demikian budaya organisasi memberikan kontribusi yang relatif rendah yaitu 18,60\% terhadap kinerja. Artinya, guru yang puas memiliki kecenderungan untuk meningkatkan kinerja mereka. Karena karyawan yang puas sangat cenderung memberikan kualitas kinerja tinggi dan ketidakhadiran dan omzet rendah (Anghelache, 2014; Chaudhry et al., 2013; Bruce dan Blackburn, 1992). Hasilnya juga didukung oleh Kennedy, (2013) yang menyatakan bahwa insentif atau penghargaan merupakan aspek kepuasan kerja.

Dilaporkan juga bahwa kompensasi sebagai salah satu dari tiga penghargaan kepuasan kerja teratas pada karyawan organisasi. Usop et al. (2013) menemukan bahwa kepuasan kerja guru sangat berkorelasi dengan kinerja (Hutabarat 2015b). Seorang guru yang puas dianggap sebagai orang yang produktif (Anghelache, 2014; Chaudhry et al., 2013; Usop et al., 2013; Bruce dan Blackburn, 1992) dan ingin bekerja lebih keras dan memberikan dampak yang tinggi terhadap prestasi siswa (Usop et al., 2013).

Hasil ini dapat diterima karena budaya organisasi dianggap sebagai lem organisasi yang diasumsikan dapat mendorong lingkungan organisasi yang baik kepada guru dan staf di sekolah (Hutabarat, 2015a).

\section{KESIMPULAN}

Berdasarkan analisis data dan pembahasan di atas, dapat disimpulkan bahwa: 
1. Budaya organisasi secara langsung dan tidak langsung mempengaruhi kinerja guru SMA negeri di Medan

2. Budaya organisasi dan kepuasan kerja sekaligus memberikan efek langsung dan tidak langsung yang positif terhadap kinerja guru SMA Negeri. Oleh karena itu, budaya organisasi dan kepuasan kerja dapat digunakan sebagai prediktor kinerja pekerjaan guru.

\section{DAFTAR PUSTAKA}

Adejumobi. F.T., \& Ojikutu, R.K. (2013). School climate and teacher job performance in Lagos state Nigeria. Discourse Journal of Educational Research IJER, 1(2):26-36.

Anghelache. V. 2014. Factors which determine the level of job satisfaction for kindergarten teachers. Preliminary study. Science Direct. Social and Behavioral Sciences, 127:47-52.

Array, R.D., Bouchar, T.J. et al. (1989). Job satisfaction: Environmental and genetic components. Journal of Applied Psychology, 74:187-192.

Austin, M.J., \& Classen, J. (2008). Impact of organizational Changeon Organizational Culture; Implictions for Introducing Evidence-Based Practice. Journal of Evidence-Based Social Work, 5(1/2):321359.

Ballou, D., \& Podgursky, M. (1998). The case against teacher certification. Public Interest. Summer 1998. 132, pp. 16-29. http://faculty.missouri. $\quad$ edu / podgurskym/wpcontent/uploads/1998/art1998-1.pdf

Barge, J.D. (2012). Making Education Work for all Georgians, Teacher Keys Effectiveness System Handbook.State School Superintendent. pp. 1-6. https://www.gadoe.org/SchoolImprovement/Teacher-and-LeaderEffectiveness

/Documents/TKES\%2oHandbook\%2OFI NAL\%207-18-2013.pdf

Bruce, W.M., \& Blackburn, J.W. (1992). Balancing job satisfaction and performance. Westport, CT: Quorum Books.

Cha, S. (2008). Explaining teachers' job satisfaction and actual teacher turnover: A structural equation modelling approach. Paper presented at the annual conference of the University Council for
Educational Administration, Orlando FL. pp. 1-34.

Chaudhry, A.Q., Maqbool, H., Mushtaq, H.B., et al. (2013). A Study of Job Satisfaction among Female Teachers at College Level. European Journal of Business and Management, 5(15):1-6.

Colquitt, J.A., LePine, J.A. \& Wesson, M.J. (2009). Organizational Behavior, Improving performance and Commitment in the Workplace., McGraw Hill. International Edition., Singapore.

Depdiknas. (2008). Penilaian Kinerja Guru. Direktorat Tenaga Kependidikan Direktorat Jenderal Peningkatan Mutu Pendidik Dan Tenaga Kependidikan Departemen Pendidikan Nasional, Jakarta. pp. 1-47. https:// teguhsasmitosdp1 files. wordpress .com/2010/o6/22-kode-04-b3-penilaiankinerja-guru.pdf

Ehrenberg, R.G. (2003). Studying Ourselves: The academic labor market. Journal of Labor economics, 21:267-287

Fahmi, M., Maulana, A., \& Yusuf, A.S. (2011). Teacher Certification in Indonesia: A Confusion of Means and Ends, Center for Economics and Development Studies (CEDS) Padjadjaran University. October, 2011.pp. 1-16.

Goldhaber, D. (2002). The Mistery of Good Teaching. Surveying the evidence on student achievement and teachers' characteristics. 2(1):1-5. http://educationnext.org/the-mystery-ofgood-teaching/

Hutabarat, W. (2015a). Do Organizational Structure And Organizational Culture Affect Teachers' Work Motivation To Some Extent. International Journal of Sciences: Basic and Applied Research (IJSBAR). 19(3):350-362.

Hutabarat, W. (2015b). Investigation of Teacher Job-Performance Model: Organizational Culture, Work Motivation and Job-Satisfaction. Asian Social Science, 11(18):295-304.

Iffinedo, P. (2004), "Employee Motivation and Job Satisfaction in Finish Organizations": A study employees in the OuluRegion, Finland, Master of Business Administration, Thesis, University of London.

Judge, A.T., Thorensen, C.J., Bono, J.E. et al. (2001) The Job-satisfaction-Job performance relationship,: A qualitative 
and quantitative Review. Psychological review, 127(3):376-407.

Kain, J., \& Singleton, K. (1996). Equality of educational opportunity revisited. New England Economic Review, pp. 87-111.

Kane, T.J., Rockoff, J.E., \& Staiger, D.O. (2006). What Does Certification Tell Us About Teacher Effectiveness? Evidence from New York City. pp. 1-65, Kaneon Certification. pdf. E-mail: jonah. rockoff@columbia.edu, kaneto @gse.harv ard.edu,douglas.o.staiger@dartmouth.ed u.

Kennedy, K. (2013). Employee Job Satisfaction and Engagement. The Road to Economic Recovery. A Research Report by the Society for Human Resource Management (SHRM). pp. 1-55.

Ladebo, O.J. (2005). Effect of work-related Attitudes on the Intention to Leave the Profession, An Examination of school teachers in Nigeria. Educational Management Administration \& Leadership, 33(3):355-369.

Luthans, F., \& Stajkovic, A.D. (2001). The Impact of Recognition on Employee Performance: Theory, Research and Practice, University of Nebraska, Department of Manageent Lincoln.

Michaelowa, K., \& Wittmann, V. (2014). Teacher Job Satisfaction, Student Achievement and the Cost of Primary Education - Evidence from Francophone Sub-Saharan Africa. pp. 1-34. Downloads/_7\%20(3).pdf

Miles, A., \& Sledge, S. (2006). Satisfaction, Service and Culture,: Relations from the Hotel Industry in Barzil, Mexico and Spain, Proceedings-AIB-SE (USA) Annual Meeting: Clearwater Beach. pp. 112.

Ojo, O. (2009). Impact Assessment of Corporate Culture on Employee Job Performance. Business International Journal, 2(3):389-397.

Ololube, N.P. (2009). Teacher Job Satisfaction and Motivation for School Effectuveness: An assessment, University of Heksinki, Finland. pp. 1-19. http://www.usca.edu/essays/vol182006/ ololube.pdf

Pisa. (2012). Results: Which Country Does Best at Reading, Maths and Science?.pp. 1-7.

http:/www.theguardian.com/news/databl og/2013/dec/03/pisa-results-country- bestreading-maths-science, download Feb. 21 ${ }^{\text {st }}, 2015: 10^{\prime \prime}: 26$ pm

Restu. (2010). "Pengaruh Budaya Organisasi, Kepemimpinan Transformational, Kepribadian, Kepuasan Kerja, Dan Motivasi Berprestasi Terhadap Kinerja”, Unpublished Dissertation, Universitas Negeri Medan. Medan,

Rix. J. (2010). Summative ADEPT Formal Evaluation of Classroom-Based Teachers. safe-t a guide for teachers and evaluators . South Carolina Department of Education. pp.1-75. http:/ www.ed.sc.gov /agency /programs -services/ 50/ documents /SAFETGuide Teachers Evaluators.pdf

Robin, S.P., \& Coulter, M. (2007)/ Management, Pearson International Edition, New Jersey, USA.

Saari, L.M., \& Judge, T.A. (2004). Employee Attitudes And Job Satisfaction. Human Resource Management, 43(4):395-407

Sabri. P.S.U., Ilyas. M., \& Amjad. Z. (2011). Organizational Culture and Its Impact on the Job Satisfaction of the University Teachers of Lahore, International Journal of Business and Social Science 2(24):121128.

Schein, H.E. (2004). Organizational Culrtue and Leadership., third edition, Jossey Bass., A Wiley imprint., USA

Sempane, M.E., Rieger, H.S. \& Roodt, G. (2002). Job satisfaction in relation to organisational culture. South African Journal of Industrial Psychology, 28(2): 23-45

Serrat, O. (2009). A Primer on Organizational Culture, Knowledge Solutions, ADB Asian Development Bank, Philippines, 68, p.110. www.adb.org/.../ primer organizational-culture.

Slocum, J.W., \& Hellriegel, D. (2009). Principles of Organizational Behavior, twentieth edition, South Western, Nelson Education, Ltd, Canada.

Staw, B.M., Bell, N.F. et al. (1986). Stability in the mids of Change. A Dispositional approach to job Attitudes. Journal of Applied Psychology, 70: 469-580.

Suriansyah, A. (2014). Hubungan Budaya Sekolah, Komunikasi, Dan Komitmen KerjaTerhadap Kinerja Guru Sekolah Dasar Negeri, Cakrawala Pendidikan, Oktober 2014, Th. XXXIII,. 3, pp. 358367.

Syamsudin, A. (2012). Permendiknas Peraturan Menteri Pendidikan dan 
Kebudayaan Republik Indonesia No,5 Tentang Sertifikasi Guru dalam Jabatan. Jakarta. Pp. 1-7. Downloads /permen dikbudo512.pdf

Tella, A., Ayeni, C.O., \& Popoola, S.O. (2007). Work Motivation, Job Satisfaction, and Organizational Commitment of Library Personnel in Academic and Research Libraries in Ohio State, Nigeria. Library Philosophy and Practice. April. 2007. pp. 1-16

Tetenbaum, T., \& Mulkeen, T. (1986). Designing education for the twenty-first century. Journal of High Education, $57(6): 621-636$.

Thierry, H.P. (1998). Handbook of work and organizational psychology: Organizational Psychology, 4. pp. 253-326

Tienken, C. (2008). Rankings Of International Achievement Test Performance And Economic Strength: Correlation Or Conjecture. International Journal of Education Policy \& Leadership, 3(4):1-15
Upu, H. (2014) Education Quality Improvement In Indonesia., Proceeding of International Conference On Research, Implementation And Education Of Mathematics And Sciences 2014, Yogyakarta State University, 29-34.

Usop, A.M., Askandar, D.K., LangguyuanKadtong, M., et al. (2013). Work Performance and Job Satisfaction among Teachers. International Journal of Humanities and Social Science, 3(5):245255.

Viswesvaran, C., \& Ones. D.S. (2000). Perspectives on Models of JobPerformance. International Journal of Selection and Assessment, 8(4):216-226.

Wilson, R.A., \& Barney, S. (2011). Handbook on the OSAC/AASSA. Association of American School in South America. Teacher Performance Evaluation. pp. 156. http:// www.state.gov/ documents/ organization/ 203750.pdf. 